\title{
Implementation of Quality Filter Mapping (QFM) in Hot Press Using Lean Manufacturing To Eliminate Waste
}

\section{Implementasi Quality Filter Mapping (QFM) Bagian Hot Press Menggunakan Lean Manufacturing Untuk Mengeliminasi Waste}

\author{
Muhamad Yasin ${ }^{1}$, Lukmandono $^{2}$ \\ \{muhamadyasin1312@gmail.com ${ }^{1}$, lukmandono@gmail.com² $\}$
}

Fakultas Teknologi Industri, Institut Teknologi Adhi Tama Surabaya $a^{1,2}$

\begin{abstract}
PT Sakari Sumber Abadi is a manufacturing company that is engaged in producing plywood products as its main product. This company has waste in the production line, namely in the $4.6 \mathrm{~mm}$ Birch product, including shrinkage putty, press mark, tip delemination, bubbles, ripping. Whereas for $18 \mathrm{~mm}$ Birch products, among others, press marks, putty shrinkage, concave, overlap, putty face too wide, ripping, waste in the face and delamination of the ends. What you want to achieve in this research is to eliminate the waste of $4.6 \mathrm{~mm}$ Birch Products and $18 \mathrm{~mm}$ Birch Products found in the Hot Press section in order to fulfill customer demand with the Lean Manufacturing approach. Lean Manufacturing is a systematic approach that eliminates waste and transforms processes. The results of the inspection using the Quality Filter Mapping (QFM) method obtained the largest waste in the Birch $4.6 \mathrm{~mm}$ Face $0.5 \mathrm{~mm}$ product, namely Failure to Riject by $0.82 \%$ and on Birch $18 \mathrm{~mm}$ Face $0.28 \mathrm{~mm}$ product, namely Failure to Riject by $7.1 \%$. Recommendations for improvement include standard parameters of temperature, press time and pressure.
\end{abstract}

Keywords - Filter; Lean; Manufacturing; Mapping; Quality

\begin{abstract}
Abstrak. PT Sakari Sumber Abadi merupakan salah satu perusahaan manufaktur yang bergerak dalam bidang penghasil produk plywood sebagai produk utamanya. Perusahaan ini memiliki waste pada lini produksi yaitu dalam produk Birch $4.6 \mathrm{~mm}$ antara lain dempul susut, press mark, deleminasi ujung, gelembung, ripping. Sedangkan untuk produk Birch $18 \mathrm{~mm}$ antara lain press mark, dempul susut, cekung, overlap, dempul face terlalu lebar, ripping, sampah dalam face dan delaminasi ujung. yang ingin dicapai dalam penelitian ini adalah mengeliminasi waste Produk Birch $4.6 \mathrm{~mm}$ dan Produk Birch $18 \mathrm{~mm}$ yang terdapat pada bagian Hot Press dalam rangka pemenuhan permintaan customer dengan pendekatan Lean Manufacturing. Lean Manufacturing merupakan pendekatan sistematik yang mengeliminasi pemborosan serta mengubah proses. Hasil inspeksi dengan menggunakan metode Quality Filter Mapping (QFM) di dapatkan waste terbesar pada produk Birch $4.6 \mathrm{~mm}$ Face $0.5 \mathrm{~mm}$ yaitu Gagal Riject sebesar 0,82 \% dan pada produk Birch $18 \mathrm{~mm}$ Face $0.28 \mathrm{~mm}$ yaitu Gagal Riject sebesar 7,1 \%. Rekomendasi perbaikan di antaranya standart parameter temperature, press time dan pressure.
\end{abstract}

Kata Kunci - Filter; Lean; Manufacturing; Mapping; Quality

\section{Pendahuluan}

Era globalisasi menuntut segala aspek kehidupan seluruh masyarakat untuk berubah, lebih berkembang dan maju. Salah satu mekanisme yang menjadi ciri globalisasi dewasa ini adalah tekanan perdagangan yang kompetitif sehingga menuntut setiap perusahaan untuk meningkatkan keunggulan kompetitif mereka agar dapat memenangkan persaingan yang terjadi [1]. Kualitas, harga (cost), ketepatan waktu pengiriman (delivery time), dan fleksibilitas (flexibility) merupakan pengaruh ketatnya persaingan dalam dunia industri memacu perusahaan manufaktur untuk memiliki keunggulan kompetitif [2]. Meminimasi waste (pemborosan) termasuk salah satu meningkatkan keunggulan[3].

PT Sakari Sumber Abadi merupakan salah satu perusahaan manufaktur yang bergerak dalam bidang penghasil produk plywood sebagai produk utamanya. Aliran proses produksi di mulai dari rotary kemudian di teruskan ke bagian press dryer dan continus dryer lalu proses glue speader, selanjutnya masuk bagian hot press setelah itu double saw, kalibrasi, sanding dan packing.

Lean Manufacturing merupakan pendekatan sistematik yang mengeliminasi pemborosan serta mengubah proses. Hal ini dilakukan dengan mengidentifikasi dan mengurangi pemborosan dengan perbaikan yang berkelanjutan[4]. Lean Manufacturing berupaya untuk menghilangkan segala bentuk pemborosan dan megevaluasi aliran produksi sepanjang value stream serta menaikkan nilai tambah produk ke pelanggan[5].

Quality Filter Mapping (QFM) merupakan value stream mapping tools yang mampu mengevaluasi jenis waste berupa defect, overproduction, dan inappropriate processing. Pada penelitian ini, berupa pemetaan terhadap masalah kualitas produk (cacat) yang terindentifikasi pada saat operasi ataupun inspeksi merupakan Quality Filter 
Mapping (QFM) yang di gambarkan. Quality filter mapping membantu mengidentifikasi dimana cacat terjadi dan dimana mereka ditemukan[6].

\section{Konsep Dasar Lean}

Rangkaian aktivitas atau solusi untuk mengeliminasi waste, meningkatkan operasi value added (VA) dan meredukasi operasi non- value added (NVA) merupakan Secara terminologi lean [7]. Lean Manufacturing adalah cara berpikir, filosofi, metode dan strategi manajemen untuk meningkatkan efisiensi di bidang manufaktur atau produksi. Tujuan utama Lean Manufacturing adalah meningkatkan profitabilitas perusahaan dan untuk memaksimalkan nilai bagi pelanggan dengan menghilangkan Elemen Kerja yang tidak memberikan nilai tambah (waste) [8].

\section{Konsep Seven Waste}

Tuntutan yang sangat kompetitif dan standar internasional telah memaksa banyak perusahaan manufaktur untuk melakukan eliminasi waste dalam produksi untuk meningkatkan efisiensi. Gabungan model Sistem Manajemen Mutu seperti Total Quality Management (TQM) dan Lean Manufacturing System (LMS) di harapkan membantu perusahaan manufaktur memenuhi tuntutan yang sangat penting untuk dipertahankan dalam kompetitif yang terjadi[9]. Waste yaitu sebuah konsep yang diidentifikasi oleh sebagai bagian dari sistem produksi Toyota dari segala sesuatu yang tidak memberikan nilai tambah dalam sebuah proses (non value added) [10]. Secara umum terdapat 7 jenis pemborosan yang ada. Overproduction, waiting time, transportation, processes, inventories, motion, dan defect merupakan pemborosan yang di maksud. Memproduksi lebih dari pada kebutuhan pelanggan eksternal dan internal, atau memproduksi lebih cepat atau lebih awal dari pada masa kebutuhan pelanggan eksternal dan internal merupakan overproduction. Keterlambatan yang tampak melalui orang-orang yang sedang menunggu mesin, peralatan, bahan baku, supplier, perawatan/pemeliharaan (maintenance), dll; atau mesin-mesin yang sedang menunggu perawatan, orang-orang, bahan baku, peralatan, dll merupakan Delays (waiting time). Memindahkan orang atau barang ketempat yang sangat jauh dari satu proses ke proses berikut yang dapat mengakibatkan waktu penanganan material bertambah merupakan transportation. Tidak efisien merupakan processes atau mencakup proses-proses tambahan atau aktivitas kerja yang tidak perlu. Dasar dari menimbulkan aktivitas penanganan tambahan dan inventories menyembunyikan masalah yang seharusnya tidak diperlukan merupakan inventories. extra paperwork, extra space, dan extra cost, merupakan akibat dari Inventories. Jasa yang akan diserahkan kepada pelanggan dan setiap pergerakan dari orang atau mesin yang tidak menambah nilai kepada barang. Tetapi waktu saja merupakan motion dan hanya menambah biaya. Customer dissatisfaction, scrap, rework, customer returns, dan desain yang tidak memenuhi kebutuhan pelanggan serta penambahan features yang tidak perlu merupakan defect [11].

\section{Konsep Quality Filter Mapping}

Alat yang digunakan untuk mengidentifikasi permasalahan kualitas pada area aliran rantai pasok perusahaan merupakan Quality filter mapping. Cacat yang akan digambarkan hanya cacat kualitas pada produk yang ditemukan selama proses produksi [12]. Digunakan untuk evaluasi waste jenis defect. Dalam penelitian ini pada proses produksi ada defect yang terjadi di Perusahaan sebagian besar berupa scrap defect karena sebagian besar cacat tersebut dapat langsung diidentifikasi secara visual dari proses inspeksi pada setiap proses[13]. Dan digunakan untuk menganalisis waste jenis defect yang terjadi dalam proses pembuatan kantong semen kraft yang ditempel[14].Untuk meningkatkan kualitas produk perlu dilakukan pemberdayaan tenaga kerja dengan melakukan pelatihan kepada pekerjanya. Program ini diharapkan dapat meningkatkan ketrampilan tenaga kerja dalam melaksanakan pekerjaan dan mengurangi produk cacat[15].

\section{TAHAPan PENELITian}

Penelitian ini dilakukan melalui 4 tahapan yang sistematis yaitu Tahap (1). Identifikasi Masalah. Merupakan tahap awal penelitian yang berisi latar belakang dan identifikasi masalah serta penentuan tujuan penelitian. Tahap (2). Pengumpulan dan pengolahan data. Data primer dan sekunder sebagai dua data dalam tahap ini. Data primer Adalah data yang didapatkan dari pengamatan langsung dan juga didapatkan melalui penyebaran kuisioner kepada departemen yang bersangkutan dalam proses produksi, wawancara dan studi data langsung seperti mendokumentasikan proses produksi. Sedangkan untuk data sekunder meliputi data histori perusahaan, data jumlah tenaga kerja dan proses produksi. Data primer dan sekunder sebagai hasil didapatkan untuk perbaikan proses produksi. Tahap (3). Tahap Analisis. Terdiri dari Pembuatan Current State Value Stream Mapping, Identifikasi dan Pengukuran Waste, Analisa Waste dengan Metode Quaity Filter Mapping (QFM), Evaluasi Rekomendasi dan Rancangan Perbaikan. Tahap (4). Tahap Kesimpulan dan Saran. Dalam tahap ini akan ditarik kesimpulan untuk menjawab tujuan dan rumusan masalah penelitian. Selain itu juga berisi saran penelitian sehingga diharapkan menjadi penelitian yang berguna dimasa depan ,bermanfaat dan membangun. 
Procedia of Engineering and Life Science Vol.1 No. 2 Juni 2021

Seminar Nasional \& Call for Paper Fakultas Sains dan Teknologi (SENASAINS $2^{\text {nd }}$ )

Universitas Muhammadiyah Sidoarjo

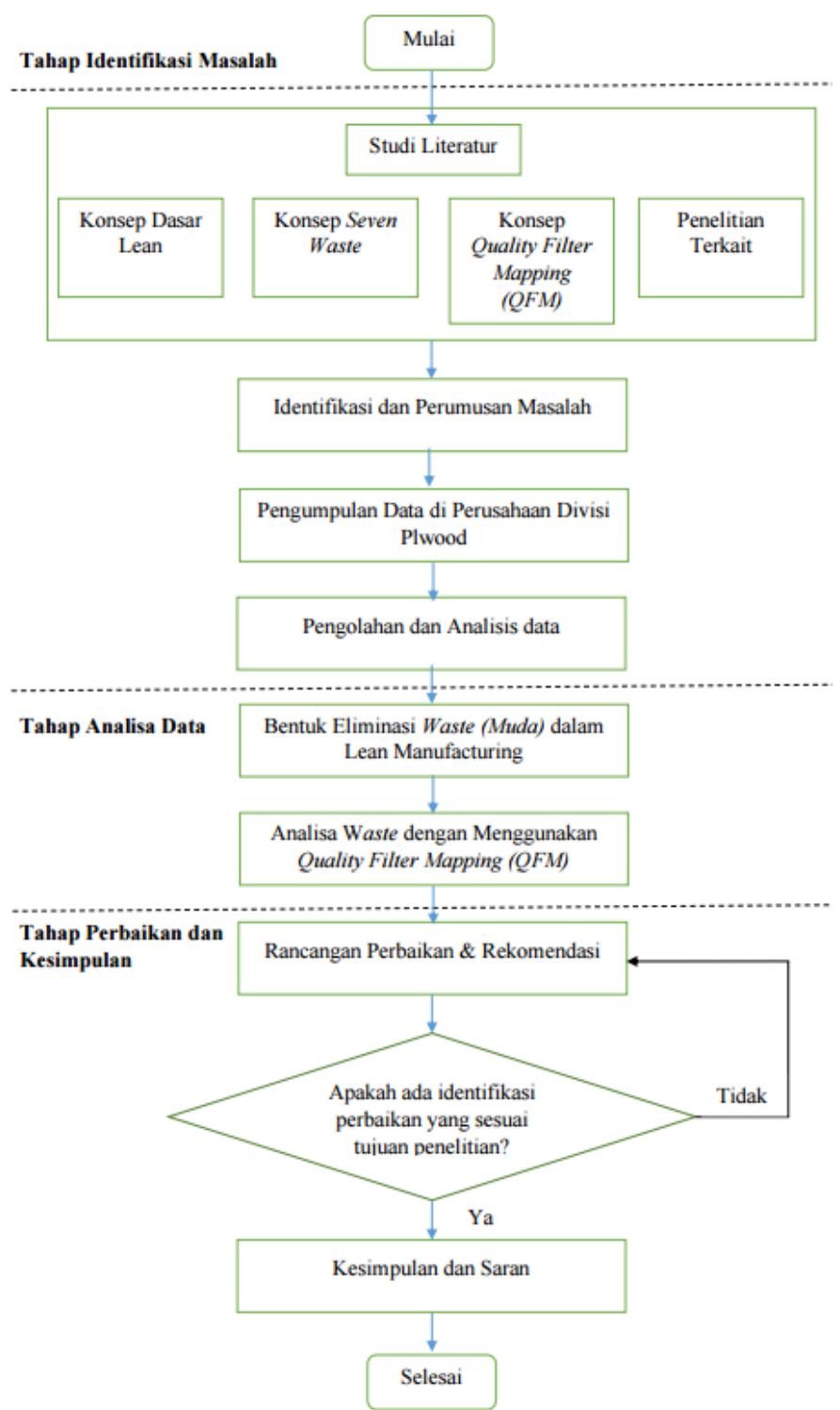

Gambar 1. Tahapan Penelitian 


\section{METODE QUALITY FILTER MAPPING}

\section{Pembahasan Data I}

Detailed Maping pada Quality Filter Mapping pada produk Birch $4.6 \mathrm{~mm}$ Face $0.5 \mathrm{~mm}$ dapat dilihat pada Tabel 1 Tabel Quality Filter Mapping pada produk Birch $4.6 \mathrm{~mm}$ Face $0.5 \mathrm{~mm}$.

Tabel 1. Quality Filter Mapping pada produk Birch $4.6 \mathrm{~mm}$ Face $0.5 \mathrm{~mm}$

\begin{tabular}{|c|c|c|c|c|c|}
\hline No & Nama Variabel & Jenis & Total & Total persentase variabel \\
& Cacat Birch 4,6 mm & Waste & persentase & pcs & persentase \\
\hline 1 & Gagal Repair & Dempul Susut & $0,41 \%$ & 14 & $0,57 \%$ \\
& & Press mark & $0,16 \%$ & & \\
\hline 3 & \multirow{2}{*}{ Gagal Reject } & Deleminasi ujung & $0,30 \%$ & 20 & $0,82 \%$ \\
& & Gelembung & $0,20 \%$ & & \\
\hline 5 & & Ripping & $0,16 \%$ & & \\
\hline 6 & & Press mark & $0,04 \%$ & & \\
\hline
\end{tabular}

Berdasarkan hasil Quality Filter Mapping pada produk Birch $4.6 \mathrm{~mm}$ Face $0.5 \mathrm{~mm}$ pada Tabel 1 persentase cacat tertinggi terjadi pada Gagal Riject sebesar $0,82 \%$, berarti kualitas produk yang dipengaruhi oleh variabel cacat Gagal Riject mengasilkan kualitas yang paling rendah.

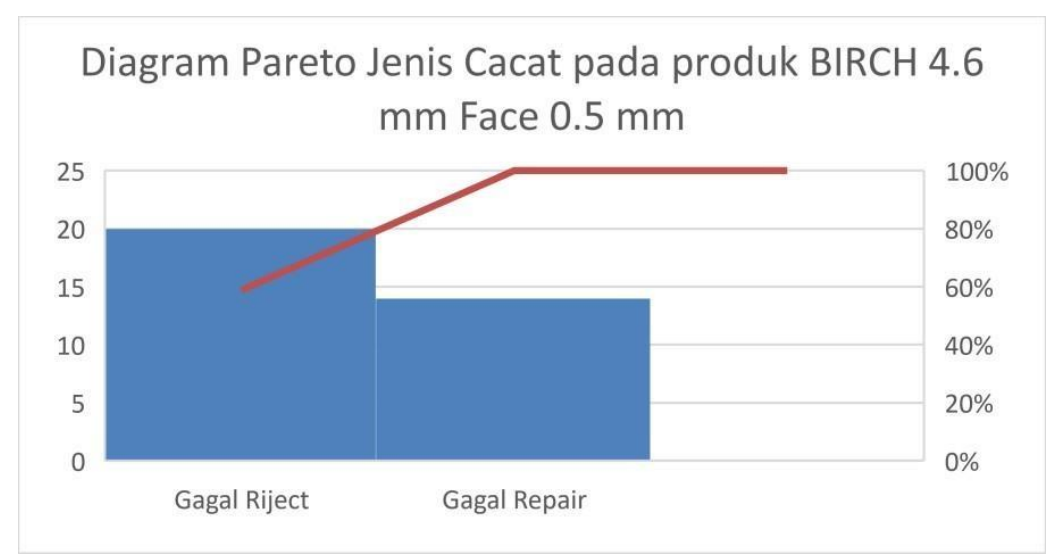

Gambar 2. Diagram Pareto Produk Birch 4.6 mm Face $0.5 \mathrm{~mm}$

Berdasarkan diagram Pareto pada Birch $4.6 \mathrm{~mm}$ Face $0.5 \mathrm{~mm}$ diperoleh urutan variabel cacat dari terbesar sampai terkecil yaitu : gagal reject dan gagal repair.

\section{Pembahasan Data II}

Detailed Maping pada Quality Filter Mapping pada produk Birch $18 \mathrm{~mm}$ Face $0.28 \mathrm{~mm}$ dapat dilihat pada Tabel 1.2 Tabel Quality Filter Mapping pada produk Birch $18 \mathrm{~mm}$ Face $0.28 \mathrm{~mm}$. 
Procedia of Engineering and Life Science Vol.1 No. 2 Juni 2021

Seminar Nasional \& Call for Paper Fakultas Sains dan Teknologi (SENASAINS 2nd)

Universitas Muhammadiyah Sidoarjo

Tabel 2. Quality Filter Mapping pada produk Birch $18 \mathrm{~mm}$ Face $0.28 \mathrm{~mm}$

\begin{tabular}{|c|c|c|c|c|c|}
\hline \multirow[t]{2}{*}{ No } & \multirow{2}{*}{$\begin{array}{c}\text { Nama Variabel } \\
\text { Cacat Birch } 18 \mathrm{~mm}\end{array}$} & \multirow{2}{*}{$\begin{array}{c}\text { Jenis } \\
\text { Waste }\end{array}$} & \multirow{2}{*}{$\begin{array}{c}\text { Total } \\
\text { persentase }\end{array}$} & \multicolumn{2}{|c|}{ Total persentase variabel } \\
\hline & & & & pcs & persentase \\
\hline 1 & Gagal Repair & Dempul Susut & $0,32 \%$ & 11 & $1,17 \%$ \\
\hline 2 & & Press mark & $0,85 \%$ & & \\
\hline 3 & Gagal Reject & Cekung void & $3,52 \%$ & 67 & $7,10 \%$ \\
\hline 4 & & Overlap & $1,81 \%$ & & \\
\hline 5 & & Dempul face lebar & $1,17 \%$ & & \\
\hline 6 & & Ripping & $0,21 \%$ & & \\
\hline 7 & & Press mark & $0,21 \%$ & & \\
\hline 8 & & Sampah dalam face & $0,11 \%$ & & \\
\hline 9 & & Deleminasi ujung & $0,11 \%$ & & \\
\hline
\end{tabular}

Hasil Quality Filter Mapping berdasarkan pada produk Birch $18 \mathrm{~mm}$ Face $0.28 \mathrm{~mm}$ pada Tabel 1.2 persentase cacat tertinggi terjadi pada Gagal Riject sebesar 7,1\%, berarti kualitas produk yang dipengaruhi oleh variabel cacat Gagal Riject mengasilkan kualitas yang paling rendah.

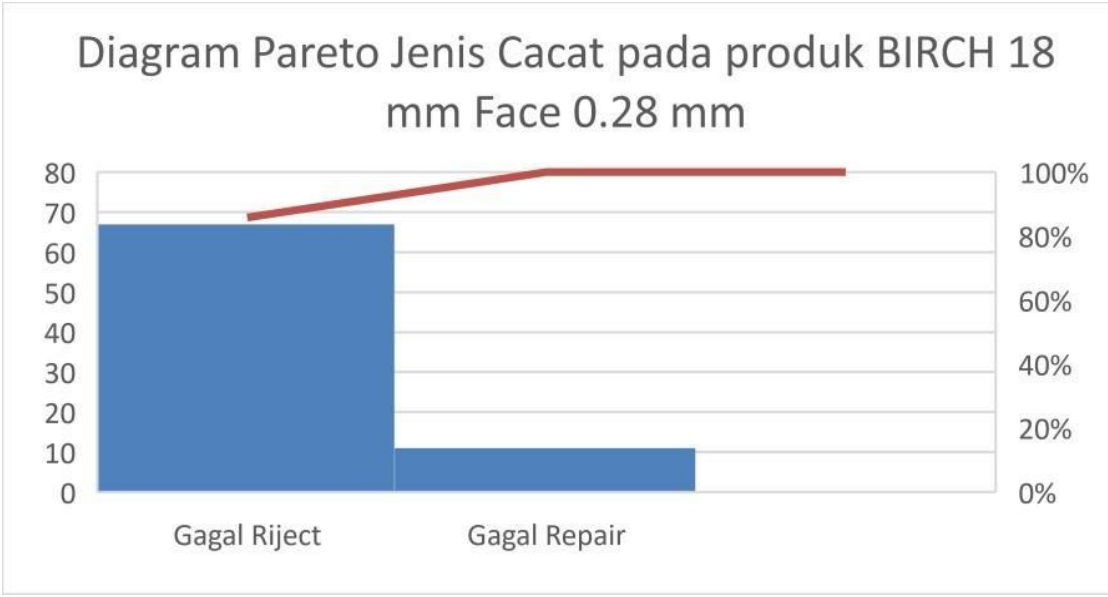

Gambar 3. Diagram Pareto Produk Birch 18 mm Face 0.28 mm

Berdasarkan diagram Pareto pada Birch $18 \mathrm{~mm}$ Face $0.28 \mathrm{~mm}$ diperoleh urutan variabel cacat dari terbesar sampai terkecil yaitu : gagal reject dan gagal repair.

\section{UPAYA ELIMINASI WASTE}

Bentuk upaya eliminasi waste adalah rekomendasi sebagai hasil dari beberapa sample inspeksi yang sudah di implementasikan sehingga adanya parameter rekomendasi perbaikan untuk mengatasi waste yang terjadi adalah (1). Standart Parameter Temperature suhu pada mesin Hot Press yaitu A. Produk Birch $4.6 \mathrm{~mm}$ Face $0.5 \mathrm{~mm}$ Temperature suhu $85^{\circ} \mathrm{C}-95^{\circ} \mathrm{C}$. B. Produk Birch $18 \mathrm{~mm}$ Face $0.28 \mathrm{~mm}$ Temperature suhu $90^{\circ} \mathrm{C}-105^{\circ} \mathrm{C}$. (2). Standart Parameter Press Time pada Mesin Hot Pres yaitu A. Produk Birch $4.6 \mathrm{~mm}$ Face $0.5 \mathrm{~mm}$ : 360 Detik. B. Produk Birch $18 \mathrm{~mm}$ Face 0.28 mm : 300 Detik. (3). Standart Parameter Tekanan Hot Press (Preasure Gauge) yaitu A. Produk Birch 4.6 mm Face $0.5 \mathrm{~mm}$ : 10 Mpa. B. Produk Birch $18 \mathrm{~mm}$ Face $0.28 \mathrm{~mm}: 10 \mathrm{Mpa}$. 


\section{HASIL PENELITIAN}

Hasil implementasi dengan menggunakan metode Quality Filter Mapping (QFM) di dapatkan waste terbesar pada produk Birch $4.6 \mathrm{~mm}$ Face $0.5 \mathrm{~mm}$ yaitu Gagal Riject sebesar 0,82 \% dan pada produk Birch $18 \mathrm{~mm}$ Face $0.28 \mathrm{~mm}$ yaitu Gagal Riject sebesar 7,1\%. Hasil identifikasi dan Analia didapatkan penyebab waste yang dominan adalah (1). Produk Birch $4.6 \mathrm{~mm}$ Face $0.5 \mathrm{~mm}$. Gagal repair : 14 pcs (0,57\%) disebabkan oleh dempul susut (0.41\%), press mark $(0.16 \%)$. Gagal riject : 20 pcs $(0,82 \%)$ disebabkan oleh delaminasi ujung $(0.3 \%)$, gelembung $(0.20 \%)$, ripping $(0.16 \%)$, press mark (0.04\%). (2). Produk Birch $18 \mathrm{~mm}$ Face $0.28 \mathrm{~mm}$. Gagal repair : 11 pcs $(1,17 \%)$ disebabkan oleh dempul susut $(0.32 \%)$, press mark $(0.85 \%)$. Gagal riject : 67 pcs $(7,1 \%)$ disebabkan oleh cekung (void)(3.52\%), overlap $(1.81 \%)$, dempul face terlalu lebar $(1.17 \%)$, ripping $(0.21 \%)$, press mark $(0.21 \%)$, sampah dalam face $(0.11 \%)$, delaminasi ujung $(0.11 \%)$.

Hasil Rekomendasi perbaikan untuk mengatasi waste yang terjadi adalah (1). Standart Parameter Temperature suhu pada mesin Hot Press yaitu A. Produk Birch $4.6 \mathrm{~mm}$ Face $0.5 \mathrm{~mm}$ Temperature suhu $85^{\circ} \mathrm{C}-95^{\circ} \mathrm{C}$. B. Produk Birch $18 \mathrm{~mm}$ Face $0.28 \mathrm{~mm}$ Temperature suhu $90^{\circ} \mathrm{C}-105^{\circ} \mathrm{C}$. (2). Standart Parameter Press Time pada Mesin Hot Press yaitu A. Produk Birch $4.6 \mathrm{~mm}$ Face $0.5 \mathrm{~mm}: 360$ Detik. B. Produk Birch $18 \mathrm{~mm}$ Face $0.28 \mathrm{~mm}: 300$ Detik. (3). Standart Parameter Tekanan Hot Press (Preasure Gauge) yaitu A. Produk Birch $4.6 \mathrm{~mm}$ Face $0.5 \mathrm{~mm}: 10 \mathrm{Mpa}$. B. Produk Birch $18 \mathrm{~mm}$ Face $0.28 \mathrm{~mm}: 10 \mathrm{Mpa}$.

\section{KESIMPULAN}

Lean Manufacturing merupakan pendekatan sistematik yang mengeliminasi pemborosan serta mengubah proses. Hasil inspeksi dengan menggunakan metode Quality Filter Mapping (QFM) di dapatkan waste terbesar pada produk Birch $4.6 \mathrm{~mm}$ Face $0.5 \mathrm{~mm}$ yaitu Gagal Riject sebesar 0,82 \% dan pada produk Birch $18 \mathrm{~mm}$ Face $0.28 \mathrm{~mm}$ yaitu Gagal Riject sebesar 7,1\%. Rekomendasi perbaikan di antaranya standart parameter temperature, press time dan pressure.

\section{UCAPAN TERIMA KASIH}

Pertama saya ucapkan terimakasih kepada Bapak Lukmandono selaku Kaprodi MTI ITATS yang telah membimbing Penelitian saya, kedua saya ucapkan terimakasih kepada manajemen perusahaan PT Sakari Sumber Abadi yang telah membantu dan mengapresiasi penelitian saya, ketiga saya ucapkan terimakasih kepada orang tua saya yang telah mensupport saya, terakhir saya sangat bersyukur \& terimakasih kepada Tuhan yang maha Esa atas Nikmat dan Karuniannya.

\section{REFERENSI}

[1] Gasperz, V., \& Fontana, A. Lean Six Sigma for Manufacturing and Service Industries. Bogor: Vinchristo Publication, (2011).

[2] Khanan, M.S.A., Haryono., "Menghilangkan Pemborosan di Lini Produksi PT Adi Satria Abadi Dengan Analisa Penerapan Lean Manufacturing”, Jurnal Rekayasa Sistem Industri Vol. 4, No. 1, (2015).

[3] Farah, W.H., Putu, D.K., Hari S., 2012 "Penerapan Lean Manufacturing Untuk Mereduksi waste di PT ARISU", JURNAL TEKNIK ITS Vol. 1, No. 1 (Sept. 2012) ISSN: 2301-9271.

[4] Alaca, H., \& Ceylan, C. Value Chain Analysis the use of Value Stream Mapping: Industrial Engineering of White Good Industry Application Department (p. 6). Kuala Lumpur: International Conference on Operations Management and Industrial Engineering, (2011).

[5] Sabta Adi, Kusuma. Penerapan Lean Manufacturing Dalam Meminimasi \& Mengidentifikasi Waste Di PT. Hilton Surabaya. Undergraduate Thesis. UPN Jatim: Surabaya, (2010).

[6] Christopher Wright. (2017). Buku : Fundamentals of Assurance for Lean Project, IT Governance Ltd, 2 Mar 2017 - 156 halaman.

[7] Daonil. (2012).Tesis : Mengeliminasi Waste di Lini Produksi Machining Cast Wheel Menggunakan Metode Wam Dan Valsat Untuk Implementasi Pada Lean Manufacturing, Tahun 2012, Depok :Fakultas Teknik Program Studi Teknik Industri Universitas Indonesia.

[8] Raihanah Yusuf. Increasing Production Results at PT. Kati Kartika Murni for Planning Carton Box Production Process Improvement with Lean Manufacturing Approach. Jurnal Teknik Industri (2020) ISSN 2622-5131 (Online) Vol. 9 No. 3 ISSN 1411-6340 (Print).

[9] Ahmed Jaffar. Management of seven wastes: A case study in an automotive vendor. Article in Jurnal Teknologi $\cdot$ September 2015 DOI: 10.11113/jt.v76.5668. 
[10] Lukmandono. Minimasi Masa Penggantian Cetakan Dengan Pendekatan Singel Minute Exchange of Dies (SMED) \& Lean Manufacture. FT UMS ISSN 1412-9612, Simposium Nasional RAPI XVII (2018)

[11] Almer Panji Pradana. Implementasi Konsep Lean Manufacturing Guna Megurangi Pemborosan di Lantai Produksi, ISSN 1693-2102 http : // jurnal.upnyk.ac.id / index.php / opsi, Jurnal OPSI Vol 11 No.1 (2018).

[12] Trismi Ristyowati. Konsep Lean Manufacturing Dengan Minimasi Waste Pada Aktivitas Proses Produksi (Studi Kasus di PT. Sport Glove Indonesia). Jurnal OPSI Volume 10 Nomer 1 Juni 2017 ISSN 1693-2102.

[13] Danang Triagus Setiyawan. Perbaikan Proses Produksi Kantong Kemasan Dengan Pendekatan Lean Manufacturing untuk Minimasi Waste. Journal of Engineering and Management in Industrial System · July 2013 DOI: 10.21776/ub.jemis.2013.001.01.2.

[14] Lukmandono. Implementation Lean Manufacturing Concept of Waste Reduction at Operational Division. The 1st International Conference on Technology IOP Conf and Advanced Engineering. Series: Engineering and Materials Science 462 (2019) 012049 IOP Publishing doi : 10.1088/1757-899X/462/1/012049.

[15] Putri Citra Marifa. Waste assessment model in a hand written batik industry and Production waste analysis using value stream mapping. MATEC Web of Conferences 154, 01076 (2018), https://doi.org/10.1051/matecconf/201815401076. 